the exact time at which she touched it; she felt this to be the case, however. Before my contacting her, the witness had had no acquaintance with the phenomenon of ball lightning.

Department of Physics,

Marx Stenhoff

Royal Holloway College

Egham Hill, Egham,

Surrey TW20 OEX, UK

\section{Possible relationship between soil fulvic acid and polymaleic acid}

In the course of structural investigations into the organic matter component of soil, it became clear that the fulvic acid solutions ${ }^{1}$ (the alkali-soluble fractions of humus not precipitated by acid) contained a high proportion of their soluble organic matter as a polymer, consisting of a carbon skeleton highly substituted by carboxyl groups. The solutions also normally contained peptide and polysaccharide mixtures or complexes which could be removed almost entirely by fractionation on charcoal ${ }^{2}$, a technique which allowed the isolation of the polycarboxylic acid. Brown acidic polymers virtually identical with those found in the fulvic acid solution were recovered from podzol $\mathbf{B}_{\mathrm{h}}$ horizon humus by extraction of the soil with dilute mineral acid or trisodium citrate solutions $(p \mathrm{H} 7.0)$ followed by dialysis.

Infrared spectroscopy, elemental analysis and a study of the degradation products of these polymers and their derivatives suggested that the polymers had an aliphatic or alicyclic backbone substituted predominantly by vicinal carboxyl groups. The soil polymers still contained polysaccharide, phenolic derivatives and nitrogen, but in low amounts, the last being accountable as amino acid residues and the ammonium ion. The product arising from the hydrolysis of pyridine-catalysed homopolymerised maleic anhydride $^{3}$ was found to be chemically and structurally related to the natural polymers, as shown by the similarities between their infrared absorption spectra (Fig. 1), their analysis (polymaleic acid: C 48.76, H $3.30, \mathrm{~N} 0.82 \% ; \mathrm{B}_{\mathrm{h}}$ citrate-soluble humus : C 47.62, H 3.39, N $0.86 \%$; for comparison, fulvic acid polymer: C $46.18, \mathrm{H} 2.68, \mathrm{~N} 0.95 \%$ ) and certain of their acid-hydrolysis products (Fig. 2). The dissimilar hydrolysis products, levulinic acid and the phenolic acids, could arise from species adsorbed on to or incorporated into the natural polymer, and this was demonstrated with the synthetic polymer. Slight differences between the potentiometric titration curve of the polymaleic acid $^{4}$ and that of the soil polymer were similarly explicable, while the solution- $p H$ visible absorption spectra relationships were identical.

Fig. 1 Infrared spectra of $a$, polymaleic acid, $b$, fulvic acid in $\mathrm{KBr}$ pressed disks (1-mg sample and $170-\mathrm{mg} \mathrm{KBr}$ in a $12-\mathrm{mm}$ diameter disk). Absorption in (b) near $1,000-1,100 \mathrm{~cm}^{-1}$ is from carbohydrate.

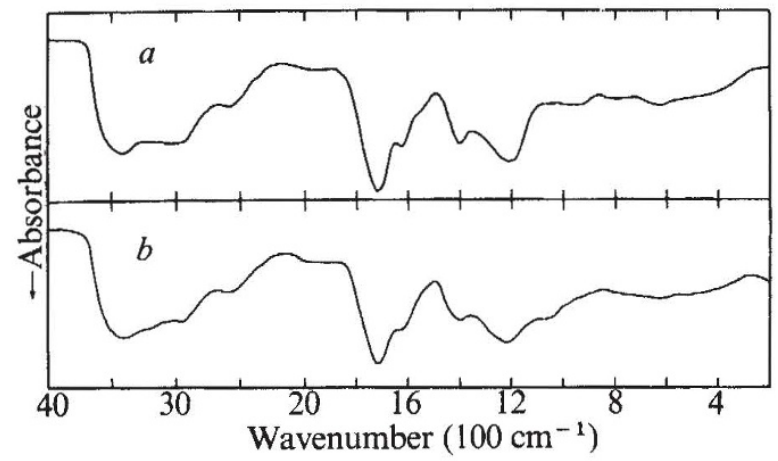

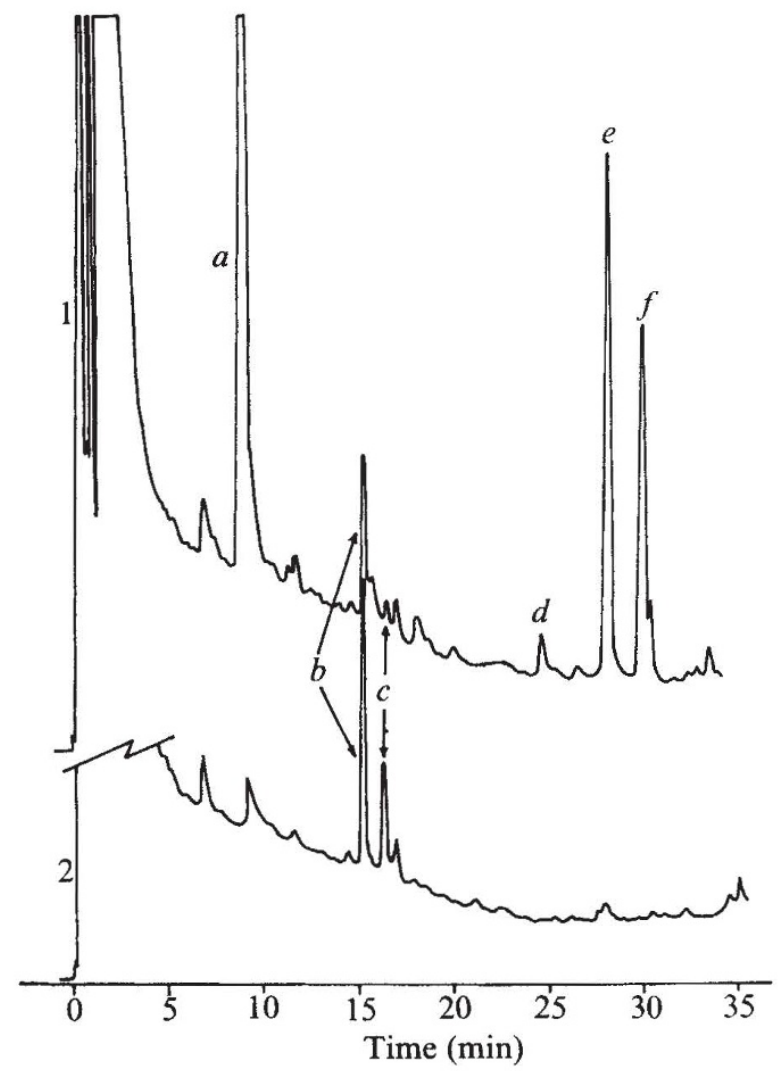

Fig. 2 Gas chromatography curves of trimethylsilyl derivatives of ether-soluble products from $6 \mathrm{M} \mathrm{HCl}$ hydrolysis of (1) Humus podzol Bh citrate-soluble humus, (2) Polymaleic acid. Products identified by gas chromatography-mass spectrometry: $a$ Levulinic acid TMS; $b$, Succinic acid di-TMS; $c$, Fumaric acid di-TMS; $d$, 4-Hydroxybenzoic acid di-TMS; $e$, Vanillic acid di-TMS; $f$, 3,4-Dihydroxybenzoic acid tri-TMS. GC conditions: $3 \% \mathrm{OV}-1$ on AW silanised Diatomite $\mathrm{C}(1.5 \times 0.006 \mathrm{~m})$; $15 \mathrm{~cm}^{3} \mathrm{~min}^{-1}$ nitrogen carrier gas; temperature programme $100{ }^{\circ} \mathrm{C}$ isothermal for $5 \mathrm{~min}, 4^{\circ} \mathrm{C}$ min $^{-1}$ to $250{ }^{\circ} \mathrm{C}$, isothermal at $250^{\circ} \mathrm{C}$ for $10 \mathrm{~min}$.

Although the complete structure of polymaleic acid has yet to be elucidated, certain aspects of the structure are known, for example, the existence of vicinal carboxyl groups readily dehydrating to yield anhydride, a property shown spectroscopically by fulvic acid, and unsaturation which accounts for an absorption band near $1,620 \mathrm{~cm}^{-1}$ in the infrared spectrum of fulvic acid. It is these features that make this polymer attractive as a model for fulvic acid. Structures already proposed ${ }^{5}$ for fulvic acid are based on aromatic residues that have been assumed to arise partly from lignin- and/or tannin-derived material. Previous unpublished work by H.A.A. and A. Hepburn has shown that the yields of aromatic molecules from degradations are sufficiently low for these compounds to be considered of minor importance in the structure. Further structural investigations of fulvic and polymaleic acids are in progress.

\section{H. A. ANDERSON J. D. Russell}

The Macaulay Institute for Soil Research, Craigiebuckler, Aberdeen, UK

Received November 22, 1975; accepted March 11, 1976.

Oden, S., Ber. dt. chem. Ges., 35, 651 (1912).

Forsyth, W. G. C., Biochem. J., 41, 176 (1947).

3 Braun, D., and Pomakis, J., Makromol. Chem. 175, 1411 (1974).

4 Barone, G., and Rizzo, E., Gazz. chim. ital., 103, 401 (1973).

5 Schnitzer, M., Agron. Abstr., 77 (1971). 